\title{
PENINGKATAN PENGETAHUAN TRANSAKSI BISNIS DALAM HUKUM BISNIS DAN SYARIAH BAGI GURU-GURU SMPN 77 JAKARTA
}

\author{
Endang Purwaningsih, ${ }^{1}$ Irfan Islami, ${ }^{2}$ Evie Rachmawati ${ }^{2}$ \\ ${ }^{1}$ Sekolah Pascasarjana dan Fakultas Hukum, Universitas YARSI \\ ${ }^{2}$ Fakultas Hukum Universitas YARSI \\ E-mail : e.purwaningsih@yarsi.ac.id.
}

\begin{abstract}
ABSTRAK
Para guru di SMPN 77 berjumlah 35 orang, sebagai subyek dan mitra pengabdian merupakan masyarakat terdidik, namun para guru tersebut belum pernah memperoleh pengetahuan maupun wawasan tentang hukum transaksi baik dalam hukum bisnis maupun hukum Islam (syariah). Para guru bekerja dan berusaha meningkatkan kualitas pembelajaran, sekaligus meningkatkan mutu kinerja dan kompetensi diri, agar mampu membawa dirinya maju, sekaligus memajukan peserta didiknya lebih maju sesuai profil lulusan yang diharapkan. Solusi yang ditawarkan adalah memberikan sosialisasi dan edukasi, dengan metode pelaksanaan kegiatan yang diterapkan adalah ceramah dan diskusi, mengutamakan partisipasi aktif para guru. Berdasarkan hasil pengabdian kepada masyarakat dapat disimpulkan: 1) penyuluhan transaksi bisnis dalam hukum bisnis dan syariah dapat meningkatkan pengetahuan para guru agar makin sadar manfaat transaksi bisnis dalam hukum bisnis dan syariah dengan dilakukan secara terprogram, sinergi antara Tim abdimas, Struktural SMPN 77 Jakarta dan peserta (guru); dan 2) faktor pendukung tumbuhnya kesadaran hukum guru terhadap transaksi bisnis dalam hukum bisnis dan syariah antara lain perkembangan era digital teknologi yang harus diadaptasi dengan baik oleh para guru dalam profesinya. Penghambat tumbuhnya kesadaran guru terhadap transaksi bisnis dalam hukum bisnis dan syariah adalah belum adanya pelatihan sebelumnya, sehingga perlu pembelajaran lebih serius agar benarbenar bisa memahami transaksi bisnis dalam hukum bisnis dan syariah.
\end{abstract}

Kata kunci: pengetahuan, guru, transaksi bisnis, hukum bisnis, syariah

\section{PENDAHULUAN}

Peranan hukum tidak hanya sebagai tool of engineering, tool of social control, namun juga hukum sebagai sarana pendidikan, hukum yang akan diberlakukan disosialisasikan terlebih dahulu kepada masyarakat agar masyarakat siap untuk menerimanya dan mematuhinya. Masyarakat diharapkan memahami dan melaksanakan hukum tidak dengan paksaan. Internalisasi hukum diharapkan terjadi, jika masyarakat sudah tahu bahwa hukum yang akan dilaksanakan akan membawa ketenteraman dan ketertiban, maka kesadaran hukum akan timbul sendiri (Manan, 2016). 
Merujuk pada Pasal 1 dan 14 UU nomor 14 tahun 2005 tentang Guru dan Dosen, Guru berkewajiban:

a. Merencanakan pembelajaran, melaksanakan proses pembelajaran yang bermutu, serta menilai dan mengevaluasi hasil pembelajaran

b. Meningkatkan dan mengembangkan kualifikasi akademik dan kompetensi secara berkelanjutan sejalan dengan perkembangan ilmu pengetahuan, teknologi dan seni

c. Bertindak obyektif dan tidak diskriminatif atas dasar pertimbangan jenis kelamin, agama, suku, ras dan kondisi fisik tertentu atau latar belakang keluarga dan status sosial ekonomi peserta didik dalam pembelajaran

d. Menjunjung tinggi peraturan perundang-undangan, hukum, dan kode etik guru serta nilai-nilai agama dan etika

e. Memelihara dan memupuk persatuan dan kesatuan bangsa

Guru juga merupakan warga masyarakat yang harus 'melek' hukum, mampu membuka wawasannya agar makin luas dan terbuka terhadap perubahan, baik dalam dinamika berlakunya hukum positif maupun trend syariah.

Berdasarkan Pasal 1 UndangUndang nomor 14 tahun 2005 tentang Guru dan Dosen, Guru adalah pendidik profesional dengan tugas utama mendidik, mengajar, membimbing, mengarahkan, melatih, menilai, dan mengevaluasi peserta didik pada pendidikan anak usia dini jalur pendidikan formal, pendidikan dasar, dan pendidikan menengah. Dalam aspek pengetahuan transaksi bisnis oleh guru, pernah dilakukan penelitian oleh Leong dan Petkova (2019) yang mengatakan:

"Many schools pioneered the development of e-commerce programs. Relevant curricula at undergraduate and graduate levels were developed. Several conference and journal papers are treating the problems related to teaching e-commerce. All of them agree that new pedagogies are needed in order to successfully teach e-commerce. One of them is Active learning, which has not been explored so far with respect to the field of teaching $e$ commerce. E-commerce is a field naturally suited for active learning."

Banyak sekolah mempelopori pengembangan program e-commerce. Kurikulum yang relevan di tingkat 
sarjana dan pascasarjana dikembangkan. Beberapa konferensi dan makalah jurnal menangani masalah yang berkaitan dengan pengajaran e-commerce. Mereka semua setuju itu diperlukan pedagogi baru untuk berhasil mengajar $e$ commerce. Salah satunya adalah Active learning, yang belum dieksplorasi sejauh ini sehubungan dengan bidang pengajaran e commerce. E-commerce adalah bidang yang secara alami cocok untuk pembelajaran aktif.

Betapa dahsyatnya informasi elektronik ini sehingga akhir-akhir ini pun terdapat banyak berita bohong (hoax) yang mengakibatkan kriminalitas terjadi, korban yang tak bersalah pun bergelimpangan. Anak didik tentu saja harus dibekali pengetahuan tentang UU ITE sekaligus pengayaan materi bagi para gurunya agar bisa membimbing anak didiknya berpikir positif dan bijak menggunakan informasi elektronik. Munculnya teknologi baru seperti internet dan jaringan lain telah mengubah dunia bisnis dan memberikan proses perdagangan dalam e-bisnis lebih efisien. Kemajuan teknologi ini telah membawa proses e-bisnis sebagai cara yang lebih cepat untuk melakukan transaksi bisnis, berbeda dari transaksi konvensional berbasis kertas karena langkah-langkah yang diperlukan untuk e-bisnis diawali dengan e-kontrak dapat dianggap lebih praktis daripada kontrak tradisional biasa (Law Student, 2018). Tak kalah pentingnya juga sebagai warga Indonesia yang mayoritas muslim, khususnya kalangan guru perlu mengetahui secara mendalam transaksi yang sesuai dengan prinsip islam, supaya terlindungi baik dari sisi hukum positif maupun hukum islam, dan menopang peningkatan kompetensi diri dalam menunjang capaian kinerja guru agar makin berkualitas.

Guru menjadi tulang punggung pembangunan, tak terkecuali pembangunan hukum. Pembangunan hukum harus bertujuan untuk mensejahterakan masyarakat, dengan kata lain pembangunan harus memiliki konotasi positif terhadap perkembangan budaya masyarakat (Salman dan Susanto, 2006) Partisipasi publik dan kesadaran hukum untuk itu mutlak diperlukan. Aspek budaya hukum merupakan suatu komponen dari sistem hukum yang konsepnya baru diperkenalkan sejak tahun 50-an dengan menimbang bahwa tindakan manusia termasuk tindakan hukumnya tidak hanya bermuatan biologis, melainkan juga sosio kultural. Untuk menata dan 
membangun kesadaran hukum diperlukan pembangunan moral secara berkesinambungan, yang tentu saja harus sinergi dengan pembangunan kesejahteraan. Lemahnya kesadaran hukum di Indonesia antara lain disebabkan oleh: (1) kurangnya kepastian hukum, (2) adanya perlakuan yang berbeda terhadap warga masyarakat dan (3) masih lemahnya komitmen dari pihak penguasa dalam pelaksanaan hukum di masyarakat.

Dalam Pasal 14 Undang-Undang Nomor 14 Tahun 2005 tentang Guru dan Dosen, dinyatakan antara lain hak guru untuk mendapatkan peluang untuk meningkatkan kompetensi; dan memperoleh dan memanfaatkan fasilitas dan infrastruktur pembelajaran untuk mendukung kelancaran fungsi profesionalisme. Jadi pantas jika guru memiliki pengetahuan terkait ecommerce dengan baik. Faktor-faktor yang mendukung tumbuhnya kesadaran hukum guru e-commerce termasuk perkembangan era digital teknologi yang harus disesuaikan dengan baik oleh guru dalam profesi mereka (Purwaningsih, Yusuf, \& Bakry, 2019).

Para guru di SMPN 77 berjumlah 35 orang, sebagai subyek dan mitra pengabdian merupakan masyarakat terdidik, namun para guru tersebut belum pernah memperoleh pengetahuan maupun wawasan tentang hukum transaksi baik dalam hukum bisnis maupun hukum islam (syariah). Para guru bekerja berusaha meningkatkan kualitas pembelajaran, sekaligus meningkatkan mutu kinerja dan kompetensi diri, agar mampu membawa dirinya maju, sekaligus memajukan peserta didiknya lebih maju sesuai profil lulusan yang diharapkan.

Kepala Sekolah SMPN 77 (2019) menyatakan bahwa pihaknya sangat terbuka bagi kegiatan yang bersifat membangun prestasi dan peningkatan kualitas guru, dan selama ini para guru SMPN 77 belum pernah mengikuti pelatihan atau pun penyuluhan tentang hukum transaksi. Mereka melakukan transaksi baik secara konvensional maupun e-commerce, namun belum memahami kepastian hukum pelindungan transaksi bisnis tersebut. Mereka juga belum mengetahui secara mendalam tentang transaksi bisnis dalam konsep syariah. Diharapkan kompetensi guru meningkat, seiring pengetahuan yang makin luas wawasannya dan tentu menambah kompetensi guru guna meningkatkan kinerja guru SMPN 77 Jakarta Pusat. 
Guna meningkatkan kompetensi guru SMPN 77, khususnya dalam pemahaman transaksi baik dari sisi hukum bisnis dan syariah, perlu dilakukan edukasi oleh Tim Abdimas melalui kegiatan pengabdian kepada masyarakat ini.

Hal ini sesuai dengan hasil pengabdian Listiyani \& Ambarsari (2018) Yang menyimpulkan bahwa guru memang perlu diikutsertakan dalam proses edukasi dan sosialisasi hukum tidak terkecuali hukum lingkungan dalam rangka menciptakan lingkungan hidup yang baik dan sehat, sehingga bisa menularkan ilmu dan pengalamannya kepada siswa.

Realitas yang senada juga dikemukakan oleh Putra (2018) bawa sosialisasi sebuah produk hukum termasuk kebijakan mempunyai peran yang sangat baik dalam rangka proses edukasi dan internalisasi ilmu pengetahuan dan informasi kepada khalayak masyarakat, agar masyarakat mengetahui berbagai kebijakan yang dibuat oleh pemerintah.

Tidak ubahnya pendapat Mukhibad \& Jayanto (2017) guru mempunyai peran penting dalam sosialisasi dan edukasi, sehingga pengetahuan yang diterima bisa disampaikan kepada seluruh siswa didiknya.

Berdasarkan uraian di atas, maka dapat dirumuskan permasalahan mitra yang akan disikapi adalah bagaimanakah upaya edukasi dilakukan terhadap guru-guru SMPN 77 Cempaka Putih Jakarta Pusat guna meningkatkan pengetahuan hukum guru tentang transaksi dalam hukum bisnis dan syariah?

Mempertimbangkan guru-guru SMPN 77 Cempaka Putih Jakarta Pusat ini belum pernah memperoleh penyuluhan materi transaksi bisnis baik dalam hukum positif maupun syariah, bisa dipahami jika pengetahuan para guru masih cukup rendah tentang transaksi bisnis, tentu ada baiknya jika dilakukan penyuluhan hukum tentang transaksi bisnis termasuk transaksi elektronik, dan konsep transaksi menurut hukum islam guna mengedukasi dan meningkatkan pengetahuan para guru SMPN 77 Jakarta Pusat. Jadi solusi yang ditawarkan adalah memberikan sosialisasi regulasi tentang transaksi bisnis baik dari Hukum Positif maupun Syariah, serta mengedukasi agar terjadi peningkatan pengetahuan hukum para 
guru SMPN 77 Jakarta terkait transaksi bisnis.

Tujuan yang ingin dicapai dari kegiatan ini adalah agar warga sekolah makin meningkat pengetahuan hukum informasi dan transaksi elektroniknya melalui penyuluhan hukum dalam bentuk sosialisasi regulasi dan edukasi yang dilakukan oleh Tim Sekolah Pascasarjana Universitas YARSI bekerjasama dengan Fakultas Hukum.

Hasil kegiatan ini diharapkan dapat memberikan manfaat berupa makin meningkatnya pengetahuan para guru tentang hukum transaksi bisnis baik dari sisi hukum positif maupun syariah melalui penyuluhan hukum.

\section{KHAYALAK SASARAN}

Khalayak sasaran kegiatan ini adalah guru-guru SMPN 77 Cempaka Putih Jakarta Pusat sebanyak 35 orang.

\section{METODE KEGIATAN}

Pada awalnya, tim pengabian kepada masyarakat mengadakan wawancara awal dengan Kepala SMPN 77 Jakarta tentang kebutuhan transaksi bisnis mana yang diinginkan dipelajari lebih mendalam oleh para guru. Diketahui, para guru memerlukan tambahan pengetahuan lebih mendalam mengenai hukum transaksi bisnis dalam hukum bisnis dan syariah.

Kegiatan ini telah dilaksanakan dengan menggunakan metode berikut.

\section{Ceramah dan diskusi}

Metode ini digunakan untuk menyampaikan materi penyuluhan yang bersifat kognitif namun dikemas dengan informasi yang tidak membosankan mengingat guru tetap dalam kondisi bekerja seperti biasa di kelas. Pelaksanaan metode ini digunakan waktu sebanyak $40 \%$ untuk ceramah atau penyampaian materi, sedangkan sisanya $60 \%$ digunakan untuk diskusi dan tanya jawab.

\section{Tanya Jawab/Diskusi}

Dalam metode ini, kegiatan utama yang dilaksanakan adalah pembimbingan supaya berpola positive thinking dan memancing peserta untuk berani bertanya dan menyalurkan aspirasi. Dalam metode ini, kegiatan utama yang dilaksanakan adalah pembimbingan dan pelatihan wawasan dan pengetahuan tentang transaksi bisnis dalam hukum bisnis dan syariah. Pada awalnya dilakukan pre test untuk mengungkap pengetahuan para guru secara brainstorming tentang materi transaksi baik dari sisi hukum positif maupun hukum islam, kemudian 
dilakukan pembekalan materi dengan cara sosialisasi dan diskusi, dengan metode ceramah dan latihan. Penyuluhan materi hukum ini dilakukan dengan berbagai materi tentang: 1) wawasan dan pengetahuan tentang transaksi bisnis menurut hukum bisnis dan 2) wawasan dan pengetahuan tentang transaksi bisnis menurut hukum Islam

\section{Monitoring dan Evaluasi}

Hasil kegiatan ini dipantau dalam waktu 3 bulan kemudian setelah penyuluhan dan pelatihan untuk melihat hasil sesuai dengan perkembangan yang diharapkan.

\section{HASIL DAN PEMBAHASAN}

Kegiatan telah dilaksanakan dengan baik, dilaksanakan di aula SMPN 77 Jakarta periode Oktober 2019 hingga Februari 2020, dan diikuti oleh seluruh guru SMPN 77 Jakarta Pusat. Terjadi peningkatan pengetahuan guru SMPN 77 Jakarta yang signifikan tentang transaksi bisnis dalam hukum bisnis dan syariah (74-84\%). Demikian juga diketahui bahwa penyuluhan tentang transaksi bisnis dalam hukum bisnis dan syariah dapat meningkatkan pengetahuan para guru tentang tentang transaksi bisnis dalam hukum bisnis dan syariah dengan dilakukan secara terprogram, sinergi antara Tim abdimas, Struktural SMPN 77 Jakarta dan peserta (guru).

Ciri khas bisnis syariah menurut Mardani (2014) bahwa bisnis Syariah merupakan implementasi dari aturan syariat Allah, dan yang membedakan islam dengan materialism adalah bahwa islam tidak pernah memisahkan ekonomi dan etika, sebagaimana tidak pernah memisahkan ilmu dan akhlak, politik dan etika, perang dan etika, serta kerabat sedarah dan sedaging dengan kehidupan islam.

Menurut Saliman (2017) dalam praktek bisnis yang menjadi sumber dari kontrak meliputi dua aspek pokok yakni aspek kontrak (perjanjian) itu sendiri, yang menjadi sumber hukum utama, di mana masing-masing pihak terikat untuk tunduk kepada kontrak yang telah disepakatinya; dan aspek kebebasan berkontrak, di mana para pihak bebas untuk membuat dan menentukan isi dari kontrak yang mereka sepakati.

Saat ini terdapat Undang-Undang Nomor 11 Tahun 2008 tentang Informasi dan Transaksi Elektronik (UU ITE) yang kemudian diubah sebagian dengan UU nomor 19 tahun 2016 
tentang Perubahan atas Undang-Undang nomor 11 tahun 2008 tentang Informasi dan Transaksi Elektronik. Menurut Makarim (2010), lahirnya teknologi digital telah mengakibatkan terjadinya keterpaduan ataupun konvergensi dalam perkembangan teknologi informasi, media dan telekomunikasi. Semula masing-masing teknologi seakan berjalan terpisah atau linear antara yang satu dengan yang lainnya, namun kini semua semakin menyatu. Wujud konvergensi teknologi telekomunikasi, media dan informatika (telematika) adalah lahirnya produk-produk teknologi baru yang memadukan kemampuan sistem informasi dan/atau sistem komunikasi secara elektronik (sistem elektronik) baik dalam lingkup lokal, regional maupun global.

Makarim (2010) menyatakan Pasal 15 ayat 1 UU ITE (baik pada UU lama dan baru) telah memberikan kewajiban bagi setiap penyelenggara untuk menyelenggarakan sistem elektroniknya secara andal dan aman serta bertanggungjawab terhadap beroperasinya sistem elektronik sebagaimana mestinya. Selanjutnya dalam ayat (2) dan (3) dinyatakan bahwa penyelenggara sistem elektronik bertanggungjawab terhadap penyelenggaraan sistem elektroniknya, kecuali dapat dibuktikan terjadinya keadaan memaksa, kesalahan, dan/atau kelalaian pihak pengguna sistem elektronik. Timbul pertanyaan sebagai konsekuensi dari rumusan Pasal 15 UU ITE apakah dalam praktiknya nanti pola pertanggungjawaban penyelenggara sistem elektronik akan didasarkan atas prinsip tanggungjawab atas kesalahan (liability based on fault), tanggungjawab atas kelalaian (negligence) ataukah prinsip tanggungjawab tanpa kesalahan (strict liability)? Menurutnya, dalam UU ITE prinsip yg dianut tidak dinyatakan secara tegas.

E-bisnis mempunyai dampak hukum, sebagaimana dikatakan oleh Sarabdeen (2014)

"Social media is an important communication channel for marketers. The research conducted earlier shows that more than $81 \%$ of the businesses are using social media or planning to use social media for marketing purposes. The social media is used for engagement marketing, buzz marketing, building customer relationships and to revitalize brand image. As social media marketing facilitates two way communications between the marketers 
and the users, the content generated in social media is considered trustworthy and reliable by the customers. The marketers while using the social media should be aware of the legal risks involved in social media marketing."

Media sosial adalah komunikasi yang saluran penting untuk pemasaran. Penelitian yang dilakukan menunjukkan sebelumnya bahwa lebih dari $81 \%$ bisnis menggunakan media sosial atau berencana menggunakan media sosial untuk tujuan pemasaran. Sosial media digunakan untuk pemasaran keterlibatan, pemasaran, membangun hubungan pelanggan dan merevitalisasi citra merek. Sebagai media sosial pemasaran memfasilitasi komunikasi dua arah antara pemasar dan pengguna, konten yang dihasilkan di media sosial dianggap dapat dipercaya dan diandalkan oleh pelanggan. Para pemasar saat menggunakan media sosial harus mewaspadai risiko hukum yang terlibat dalam pemasaran media sosial.

$$
\text { Dalam konsep islam, }
$$
pedoman umum dalam bentuk internalisasi kaidah-kaidah hukum Islam yang universal dalam praktik bisnis syariah secara khusus dapat dikategorikan ke dalam 2 (dua) hal, yaitu: 1) hal-hal yang dilarang untuk dilakukan dalam kegiatan bisnis, dalam Muamalah obyek perdagangan atau perniagaan harus halâl dan thayyib menurut asas sukarela ('antaradhin) dan 2) pengelolaan yang berdasarkan saling percaya (amanah). Konsep obyek halal lebih menekankan adanya unsur halal dan bukan berbisnis yang diharamkan oleh Islam, mengacu pada Q.S. An-Nisâ' (4): 29 dengan kalimat 'antaradhin minkum yang berarti saling sukarela atau tidak ada paksaan.

Menurut Koswara (2009) dalam tulisannya "Legalisasi software melalui open source"; mengingat pentingnya peran teknologi informasi dalam kehidupan masyarakat terkait dengan pertumbuhan perekonomian. Perlu peningkatan kemandirian, daya saing, kreativitas serta inovasi bangsa sebagai kunci utama keberhasilan pembangunan bangsa Indonesia.

Menurut Prihatman (2009) dalam tulisannya "Wimax dan peluang industri dalam negeri”, fortifikasi atas gempuran sofware impor telah membangunkan ABG (academicians, businessmen, government) untuk kemudian menggelorakan semangat Indonesia Go Open Source! (IGOS) pada awal 2004, yaitu semangat membangun piranti 
lunak yang memenuhi kebutuhan mendasar bagi pengguna komputer tanpa kekawatiran melanggar HKI dan tanpa pemborosan uang untuk membayar lisensi yang harus dibayarkan kepada pemilik yang notabene menjadi dampak negatif atau ancaman globalisasi.

Berikut rincian hasil kuesioner terhadap peserta berjumlah 35 guru.

\section{Pemahaman Perbedaan Transaksi}

Bisnis dalam hukum positif dan syariah

Sebelum pelatihan, jumlah guru yang belum memahami tentang perbedaan transaksi bisnis dalam hukum positif dan syariah dalam arti hanya mendapatkan skor 3 ke bawah sebanyak 30 orang, akan tetapi setelah pelatihan, jumlah guru yang mendapatkan skor tiga ke bawah hanya 2 orang. Terdapat kenaikan pemahaman perbedaan transaksi bisnis dalam hukum positif dan syariah $(80 \%)$.

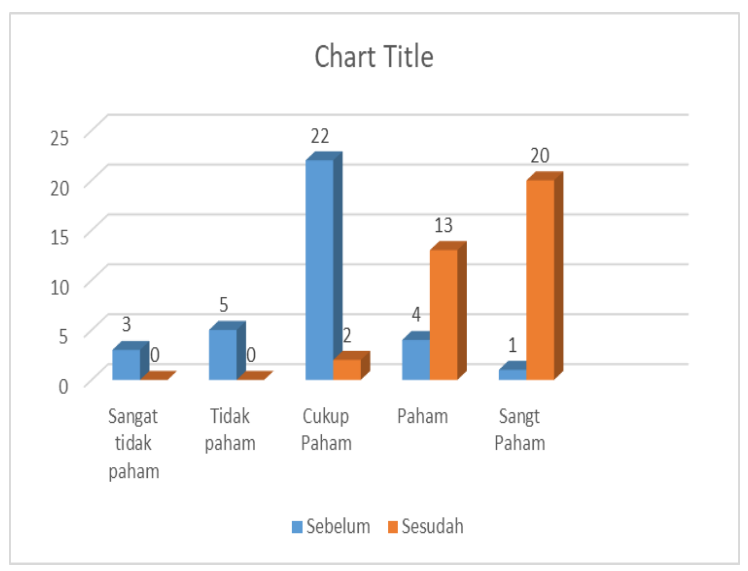

Diagram 1.Pemahaman Perbedaan

Transaksi Bisnis dalam hukum positif dan syariah

\section{Pemahaman}

pra-kontraktual,

kontraktual, dan post kontraktual

\section{dalam hukum positif}

Sebelum pelatihan, jumlah guru yang belum memahami tentang prakontraktual, kontraktual, dan post kontraktual dalam hukum positif dalam arti hanya mendapatkan skor 3 ke bawah sebanyak 30 orang, akan tetapi setelah pelatihan, jumlah guru yang mendapatkan skor tiga ke bawah hanya 1 orang. Sehingga ada kenaikan kemampuan guru dalam memahami prakontraktual, kontraktual, dan post kontraktual dalam hukum positif sebanyak 29 orang (82\%).

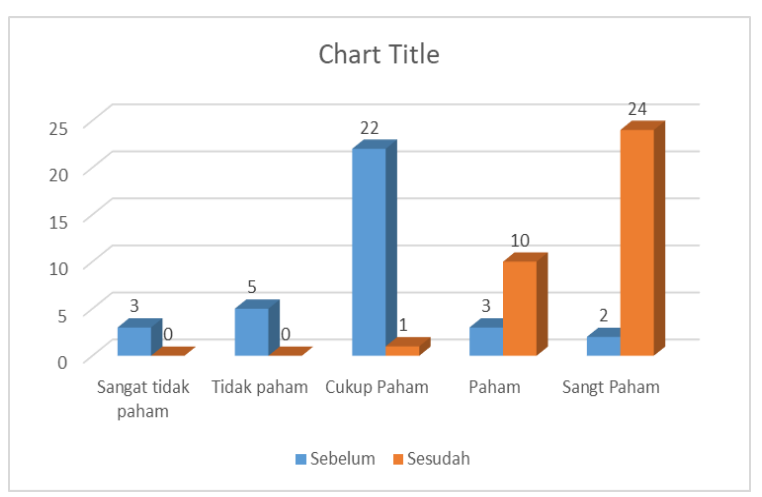

Diagram 2. Pemahaman prakontraktual, kontraktual, dan post kontraktual dalam hukum positif 


\section{Pemahaman syarat syahnya perjanjian}

Sebelum pelatihan, jumlah guru yang belum memahami tentang syarat syahnya Perjanjian dalam arti hanya mendapatkan skor 3 ke bawah sebanyak 29 orang, akan tetapi setelah pelatihan, jumlah guru yang mendapatkan skor tiga ke bawah tidak ada seorang pun. Sehingga ada kenaikan kemampuan memahami guru terkait syarat syahnya perjanjian sebanyak 29 orang (82\%).

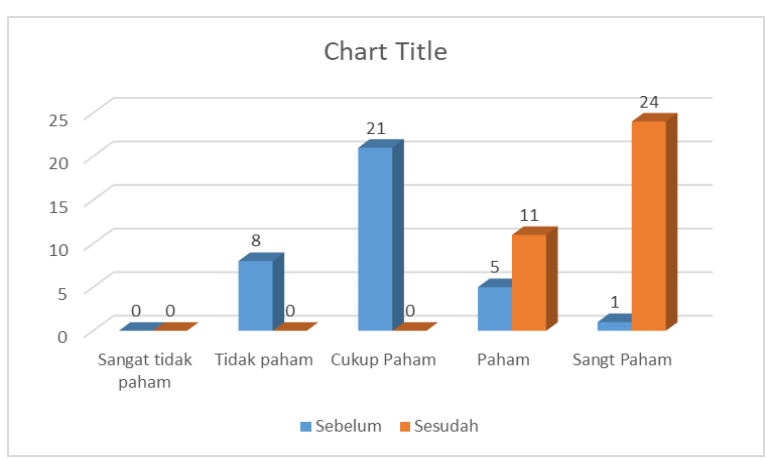

Diagram 3. Pemahaman syarat syahnya perjanjian

\section{Pemahaman bentuk-bentuk akad}

\section{dalam transaksi berbasis syariah}

Sebelum pelatihan, jumlah guru yang belum memahami tentang bentukbentuk akad dalam traksaksi berbasis syariah dalam arti hanya mendapatkan skor 3 ke bawah sebanyak 30 orang, akan tetapi setelah pelatihan, jumlah guru yang mendapatkan skor tiga ke bawah sebanyak 2 orang. Sehingga ada kenaikan kemampuan guru dalam memahami bentuk-bentuk akad dalam transaksi berbasis syariah sebanyak 28 orang $(80 \%)$.

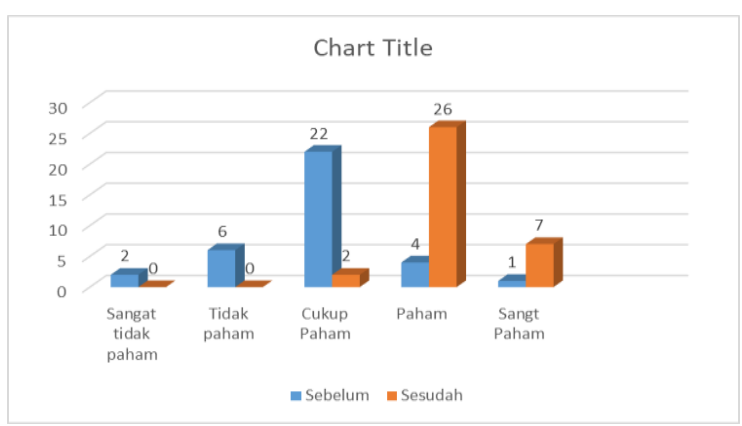

Diagram 4. Pemahaman bentuk-bentuk akad dalam traksaksi berbasis syariah

\section{Pemahaman transaksi yang syah menurut syariah}

Sebelum pelatihan, jumlah guru yang belum memahami tentang transaksi yang syah menurut syariah dalam arti hanya mendapatkan skor 3 ke bawah sebanyak 27 orang, akan tetapi setelah pelatihan, jumlah guru yang mendapatkan skor tiga ke bawah sebanyak 1 orang. Sehingga ada kenaikan kemampuan guru dalam memahami transaksi yang syah menurut syariah, sebanyak 26 orang (74\%).

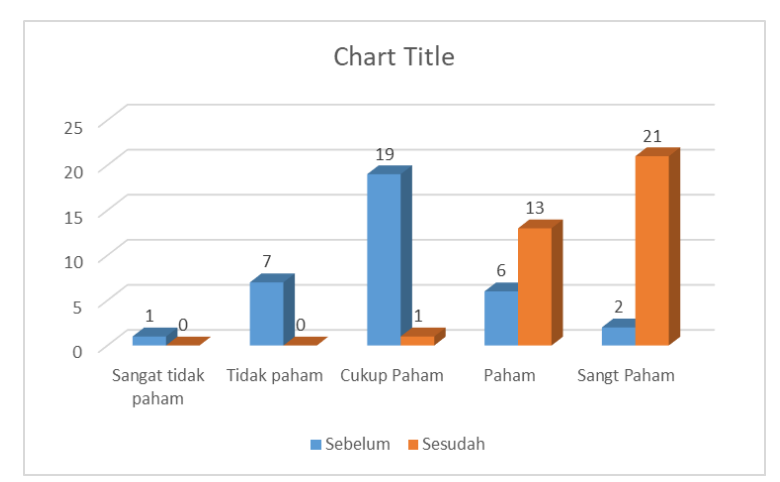


Diagram 5. Pemahaman transaksi yang syah menurut Syariah

\section{Pemahaman tentang informasi dan} transaksi elektronik dan $e$ commerce

Sebelum pelatihan, jumlah guru yang belum memahami tentang Informasi dan transaksi elektronik dan e-commerce dalam arti hanya mendapatkan skor 3 ke bawah sebanyak 29 orang, akan tetapi setelah pelatihan, jumlah guru yang mendapatkan skor tiga ke bawah sebanyak 1 orang. Sehingga ada kenaikan kemampuan guru dalam memahami informasi dan transaksi elektronik dan e-commerce, sebanyak 28 orang $(80 \%)$.

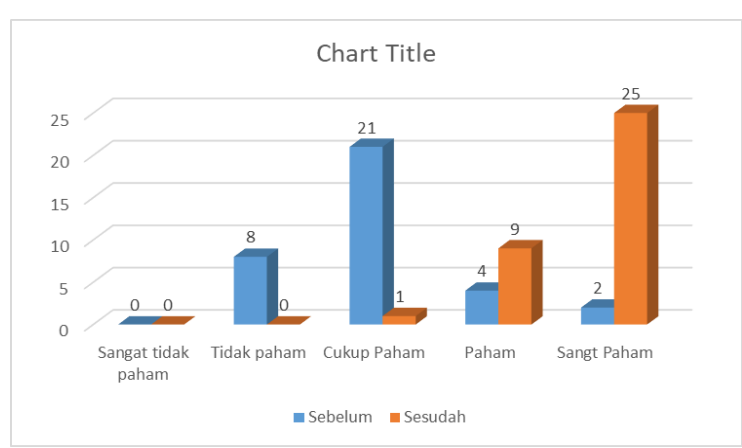

Diagram 6. Pemahaman tentang informasi dan transaksi elektronik dan e-commerce

\section{Pemahaman cara bijak bermedia} sosial dan bertransaksi online agar terlindungi hukum

Sebelum pelatihan, jumlah guru yang belum memahami tentang cara bijak bermedia sosial dan bertransaksi online agar terlindungi hukum dalam arti hanya mendapatkan skor 3 ke bawah sebanyak 29 orang, akan tetapi setelah pelatihan, jumlah guru yang mendapatkan skor tiga ke bawah sebanyak 1 orang. Sehingga ada kenaikan kemampuan guru dalam memahami cara bijak bermedia sosial dan bertransaksi online agar terlindungi hukum, sebanyak 28 orang (80\%).

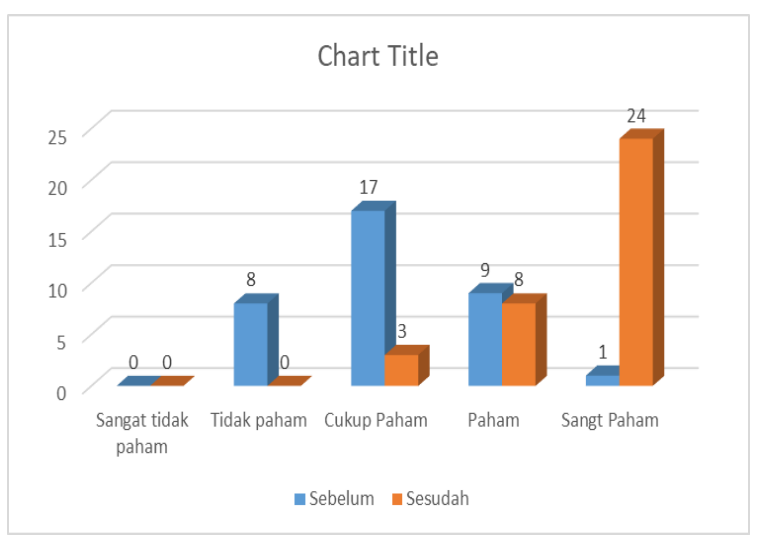

Diagram 7. Pemahaman cara bijak bermedia sosial dan bertransaksi online agar terlindungi hukum 


\section{FOTO KEGIATAN}

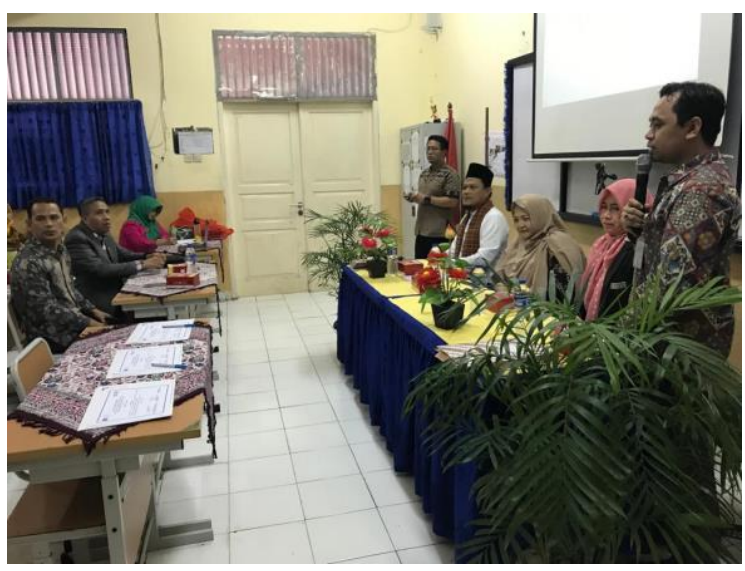

Ceramah oleh pembicara Tim

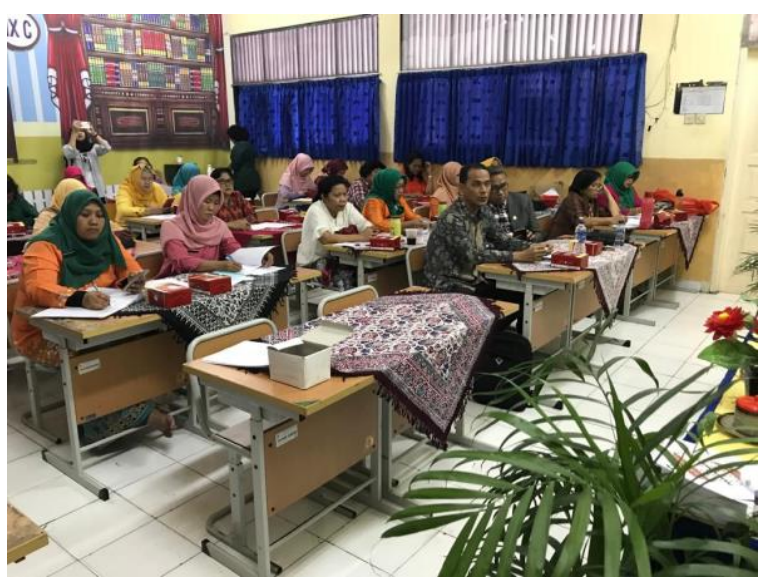

Peserta sedang Mengikuti Pelatihan dengan serius

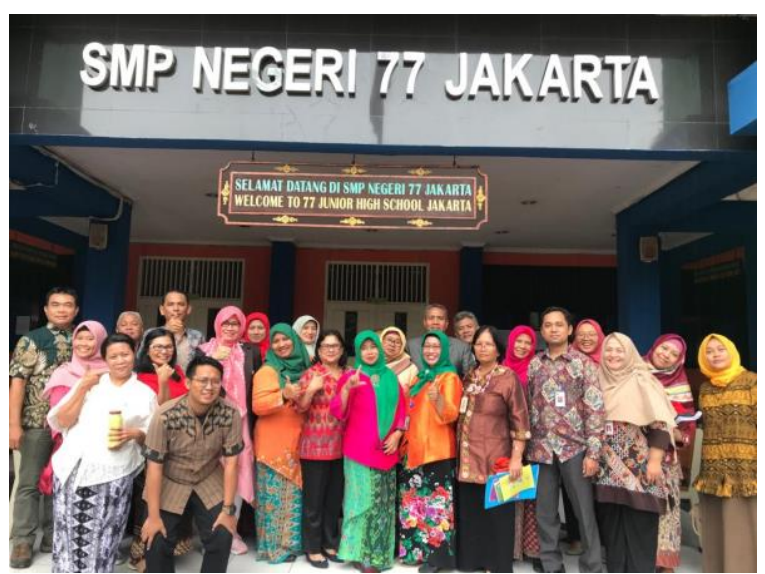

Foto bersama di lobby SMPN 77

Jakarta

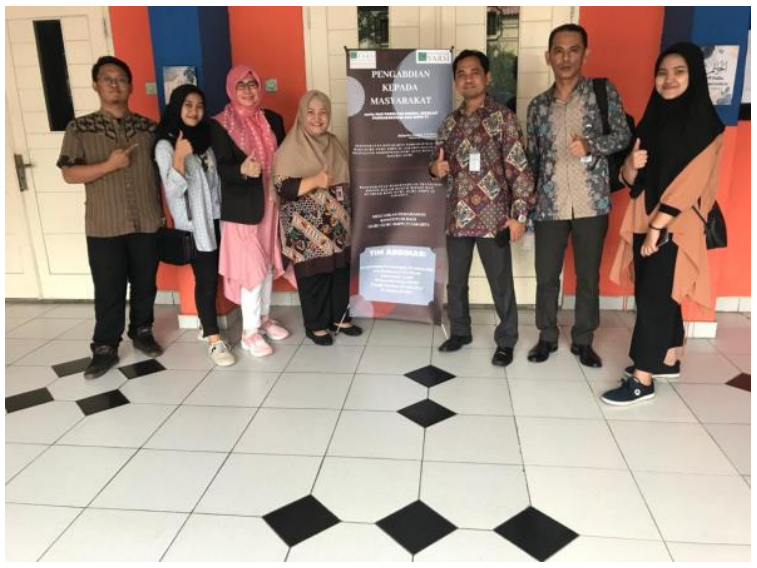

Tim Abdimas bersama mahasiswa

Universitas YARSI

\section{KESIMPULAN}

Kegiatan telah dilaksanakan dengan baik, dan terjadi peningkatan pengetahuan guru SMP N 77 Jakarta yang signifikan tentang transaksi bisnis dalam hukum bisnis dan syariah (7484\%). Demikian juga:

1. Penyuluhan transaksi bisnis dalam hukum bisnis dan syariah dapat meningkatkan pengetahuan para guru agar makin sadar manfaat transaksi bisnis dalam hukum bisnis dan syariah dengan dilakukan secara terprogram, sinergi antara Tim abdimas, Struktural SMP N 77 Jakarta dan peserta (guru).

2. Faktor pendukung tumbuhnya kesadaran hukum guru terhadap transaksi bisnis dalam hukum bisnis dan syariah antara lain 
perkembangan era digital teknologi yang harus diadaptasi dengan baik oleh para guru dalam profesinya. Penghambat tumbuhnya kesadaran guru terhadap transaksi bisnis dalam hukum bisnis dan syariah adalah belum adanya pelatihan sebelumnya, sehingga perlu pembelajaran lebih serius agar benar-benar bisa memahami transaksi bisnis dalam hukum bisnis dan syariah.

\section{UCAPAN TERIMA KASIH}

Terima kasih diucapkan kepada Yayasan, Rektor Universitas YARSI, Wakil Rektor III bidang Pengabdian kepada Masyarakat, Kepala Sekolah dan seluruh Guru SMPN 77 yang telah mendukung penyelenggaraan kegiatan ini.

\section{DAFTAR PUSTAKA}

Koswara, Engkos Koswara, Legalisasi Software melalui Open Source, dalam buku Sains dan Teknologi2, Ristek, Jakarta, Gramedia Pustaka Utama, 2009

Law student . "E commerce and $E$ Contracts". 2018. Lawteacher.net https://www.lawteacher.net/freelaw-essays/commercial-law/ecommerce-and-e-contractscommercial-law-essay.php?vref=1 diakses 23 Agustus 2019
Leong, Leslie \& Olga Petkova.

"Teaching E-Commerce: A

Platform For Active Learning."

International Business \&

Economics Research Journal, Nol

2 (3). P.1 accessed:

https://pdfs.semanticscholar.org/8

eec/3ec601402e6f928a62ace400af f58168ae8f.pdf diakses 23

Agustus 2019

Listiyani, Nurul \& Ambarsari, Ningrum. 2018. Peran Serta Pelajar dalam Penegakan Hak Asasi Manusia atas Lingkungan Hidup yang Baik dan Sehat di SMA Negeri I Bajuin. $A L$ IKHLAS Jurnal Pengabdian. Vol 3, No 2 (2018). https://ojs.uniskabjm.ac.id/index.php/AIJP/article/v iew/126

Makarim, Edmon, Tanggungjawab Hukum Penyelenggara Sistem Elektronik, Bandung, Rajagrafindo, 2010

Manan, Abdul, Peranan Hukum dalam Pembangunan Ekonomi, Jakarta, Prenadamedia Group, cet ke-2 2016

Mardani, Hukum Bisnis Syariah, Prenadamedia Group, 2014

Mukhibad, Hasan \& Jayanto, Prabowo Yudo. 2017. Pelatihan Ekonomi Syariah bagi Guru SMK sebagai Inisiasi Pembukaan Program Studi Perbankan Syariah. Al-Ikhlas Jurnal Pengabdian. Vol 3, No 1 (2017). https://ojs.uniskabjm.ac.id/index.php/AIJP/issue/vi ew/145

Prihatman, Kemal, Wimax dan Peluang Industri dalam Negeri, dalam buku Sains dan Teknologi2, Ristek, Jakarta: Gramedia Pustaka Utama, 2009 
Putra, Zainal. 2018. Sosialisasi Kebijakan Pengelolaan Dana Desa Tahun 2018 di Gampong Suak Raya Kecamatan Johan Pahlawan Kabupaten Aceh Barat Provinsi Aceh. AL-IKHLAS Jurnal Pengabdian. Vol 1, No 1. https://ojs.uniska-

bjm.ac.id/index.php/AIJP/article/v iew/1511

Purwaningsih, E. Yusuf, C, \& Bakry, R.M. 2019. Peningkatan Pengetahuan Hak Kekayaan Intelektual Guru-Guru MAN 3 Jakarta dalam Menumbuhkan Kesadaran Berkekayaan Intelektual. AL-IKHLAS Jurnal Pengabdian. Vol 4, No 2. https://ojs.uniska-

bjm.ac.id/index.php/AIJP/article/v iew/1948

Saliman, Abdul R., Hukum Bisnis untuk Perusahaan, Teori dan Contoh Kasus, Prenadamedia Group, cet ke-11, 2017
Salman, Otje dan Anton F. Susanto, Teori Hukum, Bandung: Refika Aditama, 2006

Sarabdeen, Jawahitha." Legal Risks in Social Media Marketing" International Journal of eEducation, e-Business, eManagement and e-Learning, Vol. 4, No. 3, June 2014. (p.1) Accessed: http://www.ijeeee.org/Papers/334C00017.pdf diakses 23 Agustus $\underline{2019}$

Undang-Undang nomor 14 tahun 2005 tentang Guru dan Dosen

Undang-Undang Nomor 11 Tahun 2008 tentang Informasi dan Transaksi Elektronik (UU ITE) yang kemudian diubah sebagian dengan UU Nomor 19 tahun 2016 tentang Perubahan atas Undang-Undang nomor 11 tahun 2008 tentang Informasi dan Transaksi Elektronik 